Egyptian Veterinary Medical Society of Parasitology Journal

\title{
Resistance of Rhipicephalus (Boophilus) annultus populations against Commercial Preparation of Deltamethrin, Beni-Suef, Egypt.
}

\begin{abstract}
Lilian N Mahrous and Asmaa Alaa Kamel Department of Parasitology, Faculty of Veterinary Medicine, Beni-Suef University

A field survey was conducted to evaluate susceptibility of Rhipicephalus (Boophilus) annultus to commercial deltamethrin 5\% on different localities in Beni-suef province using different bioassays (Adult immersion test AIT, Larval Packet test LPT and Esterase test). Two concentrations of deltamethrin 5\% (200 and $400 \mathrm{ppm}$ ) were tested for their acaricidal efficacy against adult $R$. (B.) annulatus collected from different localities. Adult tick mortality at $400 \mathrm{ppm}$ was higher than 200ppm and the survived females' oviposited with complete eclosion blocking for eggs. While $200 \mathrm{ppm}$ allowed eggs to hatch in all populations. The larval packet test was used to evaluate the larval mortality at six deltamethrin concentrations $(0.000625$, $0.00125,0.0025,0.005,0.010$ and 0.020). Lethal concentrations (LC50LC90), confidence intervals (CI) and slope (S) were estimated by probit analysis and the highest LC50 appeared in Ehanasia locality (0.01) but the lowest LC50 appeared in Alfashin (0.0006). Esterase assay with substerate $\alpha$ naphthylacetate applied on $R$. (B.) annulatus larvae and mean enzyme activity was determined; Ehnsaia locality appeared with the highest activity $2.373 \pm 0.058$ while Alfashin was the lowest $1.024 \pm 0.014$. From the results of this work, it was concluded that one tick population of the investigated locations was of possible susceptible, one of possible tolerant and one resistant to deltamethrin. The data generated on deltamethrin resistance status will help in formulating tick control strategy in the region.
\end{abstract}

Keywords: Rhipicephalus (Boophilus) annulatus, Adult immersion test, larval packet test, deltamethrin, Resistance-susceptibility, Egypt. 


\section{Introduction:}

Acaricides have played an important role in the control of this tick species, however , as a consequence of extensive exposures to acaricides, ticks have developed resistance to all major classes of acaricides (Jonsson et al., 1998; Rodriguez-Vivas et al., 2006; Chevillon et al., 2007). Among these acaricides the synthetic pyrethroids (deltamethrin) which is commercially available in Beni-Suef and presently the predominant acaricide used to control tick in the province. Tick resistance is defined as a significant increase in the number of individuals within a tick population that can tolerate doses of $\operatorname{drug}(\mathrm{s})$ that have proved to be lethal for most individuals of the same species (FAO, 2004). This phenomenon may be divided into four categories: behavioral, cuticular, metabolic and target site resistance. Target site resistance exists when an allele of the gene 2006). Bioassays are very useful tools to monitor resistance. The Food and Agriculture Organization of the United Nations (FAO 2004) recommends two in vitro tests to evaluate resistance against pyrethroids (deltamethrin): Larval Packet Test (LPT) and Adult Immersion Test (AIT). Each test has its own advantages and disadvantages: LPT is a laborious and time-consuming test while AIT requires many ticks for testing (Lovis et al., coding for the target molecule attacked by the acaricide has an amino acid mutation that confers resistance to the acaricide. This resistance mechanism is common in the case of pyrethroid class of acaricides (target site resistance) (Rodríguez-Vivas, et al. 2014). While the increased ability to detoxify insecticides is one of the main types of resistance (metabolic resistance). It takes place when the activity of detoxifying enzymes (esterase enzymes) is enhanced, impeding the insecticide to reach its target and evaluated by esterase assay (kumar et al., 2013). Early detection of resistance is essential in order to avoid_ further selection of resistant ticks using the same active ingredient and to delay the spread of resistance (Rodriguez-Vivas, 2003; Foil et al., 2004; Klafke et al., 2012). While biochemically esterase assay which measure the level of esterase enzymes evaluate resistance mainly against organophosphates (kumar et al., 2013). In this paper, Adult immersion and larval packet tests were used to evaluate resistance of $R$. (B.) annulatus populations in Beni-Suef province to deltamethrin (SP). Also esterase test was applied on the larvae to measure the level of esterase enzymes. 
Materials and Methods:

\section{Preparation of Acaricide:}

Commercial available deltamethrin 5\%was used and purchased from local veterinary stores (Formulated deltamethrin (Butox ${ }^{\circledR}$, EC; $5 \%$ active ingredient $<\mathrm{AI}>$ ). For experimental bioassay (LPT) stock solution of deltamethrin 5\% prepared in two parts of trichloroethylene and one part of olive oil and serial dilutions of deltamethrin were made in these diluents to generate testing doses $(0.000625$, $0.00125,0.0025,0.005,0.010$ and 0.020) and tested against the various field isolates of Rhipicephalus (Boophilus) annulatus larvae (Aguirre et al., 2000). While for adult immersion test commercial deltamethrin was diluted in distilled water to prepare two concentrations 200 and $400 \mathrm{ppm}$ to test against the various field isolates of $R$. (B.) annulatus adult

(Ravindran et al., 2014).

\section{Collection of Ticks:}

Live engorged adult female $R$. (B.) annulatus ticks were collected from different localities in Beni-Suef governorate at the time from March2014 to July 2015.After restraining of animals, engorged females tick were collected (Rodriguez-vivas et al., 2012) directly from infested animals in each locality, placed in identified carton boxes and transported to the laboratory of Parasitology at the Faculty of Veterinary medicine, Beni-Suef University.

Preparation of ticks and production of R. (B.) annulatus larvae:

Samples collected from particular area were designated as an isolate or population and washed thoroughly in distilled water and allowed to dry in paper towels, then weighted and labeled. Part of samples was kept at $27-28^{\circ} \mathrm{C}$ and $80-90$ relative humidity for laying eggs. After oviposition (14-18d), pooled eggs from all females were randomly divided into $3 \mathrm{ml}$ glass vials and plugged with a cotton cap to allow air and moisture exchange. At 7-14d after larval eclosion. One vial of larvae was used for bioassays testing Larval Packet Test (LPT) (Kemp et al., 1998) and the other was frozen at $-70{ }^{\circ} \mathrm{C}$ for esterase assay (Rodriguez-Vivas et al., 2012). The remaining engorged adult female ticks were used to estimate the acaricidal effects of respective concentration of chemical acaricide (deltamethrin) by AIT (Shyma et al., 2015).

\section{Adult immersion test (AIT):}

The Adult Immersion Test (AIT) was conducted as per the protocol described by Drummond et al. (1973). AIT has been used by various workers for evaluation of efficacy of various acaricides against Rhipicephalus (Boophilus) microplus (Jonsson et al., 2010; Gonçalve et al., 
2007; kumar et al., 2011; Sharma et al., 2012; Ravindran et al., 2014). Briefly, the engorged females of $R$. (B.) annulatus were immersed in two concentrations of deltamethrin (200 and 400ppm) for two min and then dried with filter paper before transferring into the petri dishes. After $24 \mathrm{~h}$, ticks were transferred to plastic tubes covered with muslin cloth and were kept in BOD incubator maintained at $28 \pm 1{ }^{\circ} \mathrm{C}$ and $80 \pm 5 \%$ RH. The control group was treated in similar manner with distilled water (Reghu Ravindran et al., 2014). Each concentration was replicated three times with ten adult ticks each $(n=30)$ and the following parameters were compared:

a) Mortality: recorded up to 14 days post treatment.

b) The egg mass weight laid by the live ticks.

c) Reproductive index $\quad(\mathbf{R I})=$ egg mass weight/live tick weight.

d) Percentage inhibition of oviposition $\quad(\% \mathrm{IO})=[(\mathrm{RI} \quad$ control $-\mathrm{RI}$ treated) $/$ RI control $\times 100]$.

\section{Laboratory bioassays (Larval Packet}

Test - LPT):

The LPT was performed on 12 to 14 dayold larvae as prescribed by (FAO, 2004) with some minor modifications i.e. instead of technical grade deltamethrin, commercially available formulation was used. Deltamethrin was diluted in two parts of trichloroethylene and one part of olive oil. Serial dilutions of deltamethrin $(0.000625,0.00125,0.0025,0.005,0.010$ and 0.020) were made in these diluents to generate testing doses. Diluent alone used as control. Packets were prepared by depositing $1 \mathrm{ml}$ of testing dose on a $7.5 \mathrm{~cm}$ $* 8.5 \mathrm{~cm}$ piece of whatman filter paper 1 ; then the acaricide impregnated papers were allowed to dry for $2 \mathrm{~h}$ to allow trichloroethylene to evaporate. Treated Papers were folded into half and sealed on the sides with bulldog clips to form packets, which were then sealed along the top with additional bulldog clip. The packets were placed in an incubator (26$28^{\circ} \mathrm{C}$ and $\left.85-92 \mathrm{RH}\right)$ for $24 \mathrm{~h}$. After which the papers were taken out and opened. Control packets were opened first and examined for larval mortality. Then the packets were opened in order of increasing concentration of the acaricide. Each testing dose was tested in triplicate and the average of dead and live larvae was scored. The larval mortality in larval packet test at a given testing dose was expressed as percentage from the total number of larvae (Aguirre et al., 2000).

The resistance factors (RF) for field tick isolates were calculated as the quotient between LC50 of field ticks and LC50 of a susceptible one of $R$. (B.) annulatus (Gopalan et al., 1996). On the basis of RF, the resistance levels (RL) of $R$. (B.) 
Resistance of Rhipicephalus (Boophilus) annultus

annulatus were classified as susceptible $(\mathrm{RF}<1.4)$, level I resistance $(\mathrm{RF}=1.5$ 5.0), level II resistance $(\mathrm{RF}=5.1-25.0)$, level III resistance $(\mathrm{RF}=25.1-40)$ and level IV resistance $(\mathrm{RF}>40)$ (Kumar

Sachin et al., 2011, Sharma et al., 2012).

\section{Esterase assay:}

Esterase activities with the substrate $\alpha$ naphthylacetate was determined in tick larvae according to the method of Hemingway (1998) with some modifications. Twenty deep frozen larvae from each population were homogenized in a precooled glass pestle in $200 \mu 1$ of distilled water. The homogenates were spun at $1100 \times \mathrm{g}$ in a refrigerated centrifuge at $4^{\circ} \mathrm{C}$ for $15 \mathrm{~min}$ and resulting supernatant was used for assay. Reaction mixtures contained $20 \mu \mathrm{l}$ of the homogenate in wells of microtitre plate (each sample applied in triplicate) and $200 \mu 1$ of $\alpha$-naphthylacetate solution $(250 \mu \mathrm{l}$ of $30 \mathrm{mM}$ stock in $25 \mathrm{ml}$ of phosphate buffer 0.02M, pH7.2.). The action mixtures were incubated at room temperature for $30 \mathrm{~min}$ before addition of $50 \mu \mathrm{l}$ of fast blue solution $(0.023 \mathrm{~g}$ fast blue salt dissolved in $2.25 \mathrm{ml}$ distilled water and $5.25 \mathrm{ml}$ of $5 \% \mathrm{SDS}$ in $0.1 \mathrm{M}$ sodium phosphate buffer, $\mathrm{pH} 7.2$ ) to each well. The plates were incubated for five min at room temperature and absorbance was measured at $570 \mathrm{~nm}$ in a microtitre plate reader (Tecan,Austria) operated by a personal computer using Magellan 6 software

\section{Mahrous and Kamel EVMSPJ2016 -12:11- 24}

(kumar et al., 2013).

\section{Statistical analysis:}

For the AIT all data were expressed as the mean \pm SD. using SPSS software (IBM, USA) (Reghu Ravindran et al., 2014). Probit Analysis was applied for LPT and dose response data were analyzed by probit method (Finney, 1952) with determination of lethal concentrations (LC50 and LC90) and their respective $95 \%$ confidence intervals (CI).

\section{Results:}

The questionnaire results revealed that most of farmers in Beni-Suef governorate depend mainly on deltamethrin spraying at concentration 200ppm and ivermectin injection for treatment of tick infestation. The majority of the cattle owners have reported treatment inefficiency of these chemicals in field conditions and complained repeated infestation with short intervals of application of the acaricide. The results of AIT showed in Table (1) and (2) where commercial deltamethrin $5 \%$ used with two different concentrations $200 \mathrm{ppm}$ (the field concentration applied by farmers) and $400 \mathrm{ppm}$ tested for their acaricidal activities on adult engorged female ticks Rhipicephalus (Boophilus) annulatus collected from different localities in Beni-Suef governorate. It was observed that deltamethrin at $200 \mathrm{ppm}$ produced higher level of adult mortality after 14 days in Alfashin locality only 
Resistance of Rhipicephalus (Boophilus) annultus

$83.33 \pm 4.714$, while the lowest adult mortality recorded in Ehnasis was 33.33 \pm 4.714 . Moreover, the inhibition percent of oviposition reached 100\% (no oviposition occurred) in Alfashin while in Ehnasia was 47.54 \pm 11.69 . Also 200 ppm concentration allowed hatching of the eggs laid by the treated ticks to 100 percent in all populations. While at 400ppm the adult mortality after 14 days was higher in Alfashin 86.66 \pm 4.714 and lower in Ehnasia $66.66 \pm 4.714$, the percent inhibition of oviposition was higher than $90 \%$ in most populations and reached 100\% in Alfashin but in Ehnasia population was $89.62 \pm 0.562$. It was observed complete eclosion blocking to the eggs occurred in all populations (no hatching occurred) except in Ehnasia the level of hatching was $3.33 \pm 4.714 \%$. In the present study, different populations of $R$. (B.) annulatus were surveyed by LPT showed RF (Resistance Factor) between 1 and 16.6 to deltamethrin showed in (Table 3) and the $\mathrm{LC}_{50} / \mathrm{LC}_{90}$ values for deltamethrin with their respective 95\% CI and their $\mathrm{T}$ slopes for each population were calculated. It was observed that the lowest $\mathrm{LC}_{50}$ appeared in Alfashin where the farmer did not depend on deltamethrin in control (0.0006) with 95\% CI (0.0005 to 0.0007 and $\mathrm{LC}_{90}(0.002)$ with $95 \% \mathrm{CI}(0.001$ to 0.002$)$.So, it is considered to be useful as a susceptible reference strain but the highest $\mathrm{LC}_{50}$

\section{Mahrous and Kamel EVMSPJ2016-12:11-24}

appeared in Ehanasia, where the farmers/farm owners reported frequent applications of higher doses of deltamethrin due to very low efficacy of the most aggressively marketed product, (0.01) with $95 \% \mathrm{CI}(0.005$ to 0.01$)$ and $\mathrm{LC}_{90}(0.02)$ with $95 \% \mathrm{CI}$ (0.01 to 0.02). According to the results appeared in LPT bioassay and classification described by Kumar Sachin et al. (2011) one locality can be considered susceptible (Alfashin) to deltamethrin with $\mathrm{RF}=1$ and one locality considered resistant level I or tolerant to deltamethrin with $\mathrm{RF}=3.3$ (Beni-Suef) in addition to, one locality considered resistant level II with RF varied from 16.6. Esterase activities using a general esterase substrate ( $\alpha$ naphthyl acetate) were determined within tick populations of different localities in Beni-Suef province and summarized in Table 4.The mean enzyme activity appeared in lower level in Alfashin (1.024 \pm 0.014$) \quad$ (susceptible population) but appeared in higher level in Ehnasia $\quad(2.373 \pm 0.058) \quad$ (resistant population).

\section{Discussion:}

The results of the current study revealed the presence of a widespread resistance to deltamethrin in different locality field isolates of $R$. (B.) annulatus collected from Beni-suef province, Egypt. So it appeared from the results that adult tick populations $R$. (B.) annulatus in Beni-Suef governorate 
Resistance of Rhipicephalus (Boophilus) annultus

showed resistance to deltamethrin so, to avoid development of any resistant generations of tick's in future, deltamethrin preparations should be used at or above 400 ppm that agreed with Reghu Ravindran et al. (2014) who reported above 300 ppm.

The resistance status to deltamethrin was established in different localities in BeniSuef province using LPT and the resistance factor (RF) was varied from1.00 to16.6 in larval progenies of engorged female ticks. One population showed RF below1.4 and was designated a susceptible population, one locality showed RF from 1.5 to 5.0 and was designated as resistance level I or tolerant and one locality showed RF from 5.1 to 25.0 and was designated as resistance level II according to a classification described by Kumar Sachin et al. (2011). This may be due to differences between the products used at each locality. While populations which showed RF varied from 1.6 to 8.3 were collected in area where macrocyclic lactones used beside pyrethroids, the population showed the highest RF 16.6 depended mainly on deltamethrin. Similar results reported by Kumar et al. (2013).

In the present study, higher levels of esterase enzymes were detected in the resistant populations of $R$. (B.) annulatus in Beni-suef governorate and that agreed with (Jamroz et al., 2000; Baffi et al.,
Mahrous and Kamel EVMSPJ2016 -12:11- 24

2008; Kumar et al., 2013; Li et al., 2004; Chevillon et al., 2007), (Rosario-Cruz et al., 2009; Jonsson et al., 2000) (Rodriguez-Vivas et al., 2006).

\section{Acknowledgments:}

We are thankful to the directors of this study; Dr. Magdy M Fahmy, Professor of Parasitology, Vet. Medicine, Cairo University and Dr. Shawky M Aboelhadid, Professor of Parasitology, Vet. Medicine, Beni-Suef University for guidance and supporting during this work.

\section{References:}

Aguirre , D.H.; Viñabal, A.E.; Salatin, A.O. ;Cafrune, M.M. ; olpogni, M.M.; Mangold, A.J. and Guglielmone, A.A. (2000): Susceptibility to two pyrethroids in Boophilus microplus (Acari: Ixodidae) populations of northwest Argentina reliminary results. Veterinary Parasitology. 88: 329-334.

Baffi, M.A.; Guilherme, R. L. ; Carlos, R. C. and Ana Maria, B. (2008): Esterase enzymes involved in pyrethroid and organophosphate resistance in a Brazilian population of Riphicephallus (Boophilus) microplus (Acari, Ixodidae). Mol. Biochem. Parasitol. 160:70-73.

Chevillon, C.; Ducornez, S.; de Meeûs, T.; Koffi, B.B.; Gaïa, H.; Delathière, J.M. and Barré, N. (2007): Accumulation of acaricide resistance mechanisms in Rhipicephalus (Boophilus) microplus (Acari: Ixodidae) populations from New 
Resistance of Rhipicephalus (Boophilus) annultus

Caledonia Island. Vet. Parasitol. 147 (3-4): 276-288.

Drummond, R.O.; Crust, S.F.; Trevino, J.L.; Gladney, W.J. and Graham, O.H. (1973): $B$ annulatus and $B$ decoloratus; laboratory tests of insecticides. J. Econ. Entomol. 66: 130-133.

FAO (Food Agriculture Organization), (2004): Resistance Management and Integrated Parasite Control in RuminantsGuidelines, Module 1-Ticks: Acaricide Resistance: Diagnosis, Management and Prevention.

Finney, D. J. (1952): Probit Analysis-A Statistical Treatment of the Sig-moid Response Curve, Cambridge University Press, Cambridge,UK.

Gonçalves, K.; Toigo, E.; Ascoli, B.; VonPoser, G. and Ribeiro, V.L.S. (2007): Effects of solvents and surfactant agents on the female and larvae of cattle tick Boophilus microplus, Parasitology Research. 100 (6):1267-1270.

Gopalan, N.; Prakash, S.; Bhattacharya, B.K.; Anand, O.P. and Rao, K.M. (1996): Development of malathion resistance in Culex quinque fasciatus Say (Diptera,Culicidae). Ind. J. of Med. Res. 103: 84-90.

Hemingway, J. (1998): Techniques to Detect Insecticide Resistance Mechanisms (Field and Laboratory Manual). Document WHO/CDS/CPC/MAL/98.6, World Health Organization, Geneva.
Jamroz, R.C.; Guerrero, F.D.; Pruett, J.H.; Oehler, D.D. and Miller, R.J. (2000): Molecular and biochemical survey of acaricide resistance mechanisms in larvae from Mexican strains of the southern cattle tick, Boophilus microplus. Journal of Insect Physiology. 46:685-695. Jonsson, N.N.; Mayer, D.G.; Matschoss, A.L.; Green, P.E. and Ansell, J. (1998): Production effects of cattle tick (Boophilus microplus) infestation of high yielding dairy cows. Vet. Parasitol. 78:65-77. Jonsson, N.N., Mayer, D.G. and Green, P.E., (2000): Possible risk factors on Queensland dairy farms for acaricide resistance in cattle tick (Boophilus microplus). Vet. Parasitol. 88: 79-92.

Jonsson, N.N.; Cutullè, C.; Corley, S.W. and Seddon, J.M. (2010): Identification of a Mutation in the para-sodium channel gene of the cattle tick Rhipicephalus (Boophilus) microplus associated with resistance to flumethrin but not to cypermethrin. International Journal for Parasitology 40: 1659-1664.

Kemp, D.H.; Gale, R.K.; Nari, A. and Sabatini, A.G., (1998):Acaricide resistance in the cattle ticks Boophilus microplus and B. decoloratus: review of resistance data; standardization of resistance tests and recommendations for the integrated parasite control to delay resistance. Report to Animal Health Service AGAH, FAO. CSIRO Tropical 
Agriculture, Long Pocket Laboratories, Queensland, Australia.

Kumar, S.; Paul, S.; Sharma, A.K.; Kumar, R.; Tewari,S.S.; Chaudhuri, P.; Ray, D.D.; Rawat, A.K.S. and Ghosh, S. (2011):.Diazinon resistant Status in Rhipicephalus (Boophilus) microplus collected from different agroclimatic zones of India.Veterinary Parasitology 181: 274281.

Kumar Rinesh; Gaurav Nagar; Anil Kumar Sharma; Sachin Kumar, D.D. Ray; Pallab Chaudhuri and Srikanta Ghosh. (2013): Survey of pyrethroids resistance in Indian isolates of Rhipicephalus (Boophilus) microplus: Identification of C190A mutation in the domain II of the para-sodium channel gene. Acta Tropica. (125): 237-245.

Li, A.Y.; Davey, R.B.; Miller, R.J. and George, J.E. (2004): Detection and characterization of amitraz resistance in the Southern cattle tick, Boophilus microplus (Acari:Ixodidae). Journal of Medical Entomology. 41 (2): 193-200.

Reghu Ravindran; Sunil Athalathil Ramankutty; Sanis Juliet; Adarsh Krishna Thumadath Palayullaparambil; Jyothimol Gopi; Ajith Kumar Karapparambu Gopalan; Suresh Narayanan Nair and Srikanta Ghosh (2014): Comparison of in vitro acaricidal effects of commercial preparations of cypermethrin and fenvalerate against
Rhipicephalus (Boophilus) annulatus. SpringerPlus.3:90.http://www.springerplus .com/content/3/1/90.

Rodriguez-Vivas, R.I.; Alonso-Díaz, M.A.; Rodríguez-Arevalo, F.; FragosoSanchez, H.; Santamaria, V.M. and Rosario-Cruz, R. (2006): Prevalence and potential risk factors for organophosphate and pyrethroid resistance in Boophilus microplus ticks on cattle ranches from the State of Yucatan, Mexico. Vet. Parasitol. 136: 242-335.

Rodríguez-Vivas, R.I.; Hodgkinson, J.E. and Trees, A.J (2012): Resistencia a los acaricidasen Rhipicephalus (Boophilus) microplus: situaciónactualy mecanismos de resistencia. Rev. Mex. Cienc. Pecu. 3(S1):9-24.

Rodríguez-Vivas, R.I.; Miller, R.J.; Ojeda-Chi, M.M.; Rosado-Aguilar, J.A.; Trinidad-Martínez, I.C. and Pérez de León, A.A. (2014): Acaricide and ivermectin resistance in a field population of Rhipicephalus microplus (Acari: Ixodidae) collected from red deer (Cervuselaphus) in the Mexican tropics.Vet. Parasitol. 200(1-2): 179-188.

Rosario-Cruz, R.; Almazan, C.; Miller, R.J.;

Dominguez-Gracia,D.I.; Hernandez Ortiz, R. and De la Fuente, J. (2009): Genetic basis and impact of tick acaricide resistance. Frontiers in Bioscience. 14: 2657-2665.

Sharma, A.K.; Kumar, R.; Kumar, S.; 
Nagar, G.; Singh, N.K.; Rawat, S.S.;

Dhakadd, M.L.; Rawat, A.K.S.; Ray, D.D. and Ghosh, S. (2012): Deltamethrin and cypermethrin resistance status of Rhipicephalus (Boophilus) microplus collected from six agroclimatic regions of India.Vet.Parasitol.188(3-):337-345.

Shyma, K. P.; Jay Prakash, G. ;Veer, S.; and Patel, K.K. (2015): In VitroDetection of Acaricidal Resistance Status of Rhipicephalus (Boophilus) microplus against Commercial Preparation of Deltamethrin, Flumethrin, and Fipronil from North Gujarat, India. Parasitology Research.Volume 2015, Article ID 506586,7pages.

http://dx.doi.org/10.1155/2015/506586 
Table (1) Results of adult immmersion test in different localities in Beni-Suef province, at dose 200ppm of commercial deltamethrin

\begin{tabular}{|c|c|c|c|c|c|c|c|}
\hline Location & Concentration & $\begin{array}{c}\text { Mean Adult Tick weight } \\
(\text { gm) } \pm \text { SD }\end{array}$ & $\begin{array}{c}\text { Mean Adult mortality } \\
\text { within } 14 \text { days }(\%) \\
\pm \text { SD } \\
\end{array}$ & $\begin{array}{c}\text { Mean Mass of } \\
\text { Egg weight (gm) } \\
\pm \text { SD } \\
\end{array}$ & $\begin{array}{l}\text { Reproductive index } \\
(\text { RI\%) } \pm \text { SD }\end{array}$ & $\begin{array}{l}\text { Percentage of inhibition } \\
\text { of oviposition }(\%) \pm \text { SD }\end{array}$ & $\begin{array}{l}\text { Hatching }(\%) \\
\text { visual }\end{array}$ \\
\hline \multirow[t]{2}{*}{ Ehnasia } & Control & $1.18 \pm 0.005$ & $0 \pm 0$ & $0.651 \pm 0.045$ & $0.551 \pm 0.036$ & $0 \pm 0$ & 100 \\
\hline & 200ppm & $1.109 \pm 0.031$ & $33.33 \pm 4.714$ & $0.316 \pm 0.053$ & $0.285 \pm 0.047$ & $47.54 \pm 11.69$ & 100 \\
\hline \multirow[t]{2}{*}{ Beni-Suef } & Control & $1.802 \pm 0.058$ & $0 \pm 0$ & $0.665 \pm 0.056$ & $0.368 \pm 0.019$ & $0 \pm 0$ & 100 \\
\hline & 200ppm & $1.654 \pm 0.019$ & $36.66 \pm 4.714$ & $0.071 \pm 0.016$ & $0.043 \pm 0.009$ & $87.53 \pm 3.59$ & 100 \\
\hline \multirow[t]{2}{*}{ Alfashin } & Control & $1.605 \pm 0.046$ & $0 \pm 0$ & $0.766 \pm 0.09$ & $0.479 \pm 0.067$ & $0 \pm 0$ & 100 \\
\hline & 200ppm & $1.486 \pm 0.038$ & $83.33 \pm 4.714$ & $0 \pm 0$ & $0 \pm 0$ & $100 \pm 0$ & 0 \\
\hline
\end{tabular}


Table (2) Results of adult immersion test in different localities in Beni-Suef province, at dose 400ppm of commercial deltamethrin

\begin{tabular}{|c|c|c|c|c|c|c|c|}
\hline Location & Concentration & $\begin{array}{c}\text { Mean Adult Tick weight } \\
(\text { gm) } \pm \text { SD }\end{array}$ & $\begin{array}{c}\text { Mean Adult mortality } \\
\text { within } 14 \text { days }(\%) \\
\pm \text { SD }\end{array}$ & $\begin{array}{c}\text { Mean Mass of } \\
\text { Egg weight (gm) } \\
\pm \text { SD }\end{array}$ & $\begin{array}{l}\text { Reproductive index } \\
\text { (RI\%) } \pm \text { SD }\end{array}$ & $\begin{array}{l}\text { Percentage of inhibition } \\
\text { of oviposition }(\%) \pm \text { SD }\end{array}$ & $\begin{array}{l}\text { Hatching (\%) } \\
\text { visual }\end{array}$ \\
\hline \multirow[t]{2}{*}{ Ehnasia } & Control & $1.18 \pm 0.005$ & $0 \pm 0$ & $0.651 \pm 0.045$ & $0.551 \pm 0.036$ & $0 \pm 0$ & 100 \\
\hline & 400ppm & $1.13 \pm 0.053$ & $66.66 \pm 4.714$ & $0.025 \pm 0.035$ & $0.021 \pm 0.029$ & $89.62 \pm 0.562$ & $33.33 \pm 4.714$ \\
\hline \multirow[t]{2}{*}{ Beni-Suef } & Control & $1.802 \pm 0.058$ & $0 \pm 0$ & $0.665 \pm 0.056$ & $0.368 \pm 0.019$ & $0 \pm 0$ & 100 \\
\hline & 400ppm & $1.595 \pm 0.039$ & $66.66 \pm 4.714$ & $0.007 \pm 0.01$ & $0.004 \pm 0.006$ & $98.75 \pm 1.76$ & 0 \\
\hline \multirow[t]{2}{*}{ Alfashin } & Control & $1.605 \pm 0.046$ & $0 \pm 0$ & $0.766 \pm 0.09$ & $0.479 \pm 0.067$ & $0 \pm 0$ & 100 \\
\hline & 400ppm & $1.422 \pm 0.052$ & $86.66 \pm 4.714$ & $0 \pm \mathbf{0}$ & $0 \pm 0$ & $100 \pm 0$ & 0 \\
\hline
\end{tabular}


Table 3: Lethal concentrations 50 and $90 \%$ of 14-21days-old larvae of $R$. (B) annulatus populations from different localities in Beni-Suef province calculated from larval packet tests with a commercial formulation of deltamethrin $5 \%$ :

\begin{tabular}{|c|c|c|c|c|c|c|c|c|}
\hline Location & Larvae & Slope (SE) & $\mathbf{X 2}$ & $\begin{array}{c}\mathbf{t} \text { for } \\
\text { slope }\end{array}$ & $\mathbf{L C}_{\mathbf{5 0}} \mathbf{( 9 5 \%}$ CI) & $\mathbf{L C}_{\mathbf{9 0}} \mathbf{( 9 5 \%}$ CI) & $\begin{array}{c}\text { Resistance } \\
\text { Factor(RF) }\end{array}$ & $\begin{array}{c}\text { Resistance } \\
\text { Level(RL) }\end{array}$ \\
\hline Beni-Suef & 100 & 1.93 & 5.91 & 13.14 & $\begin{array}{c}0.004 \\
0.003-0.004)\end{array}$ & $\begin{array}{c}0.01 \\
(0.008-0.01)\end{array}$ & 3.3 & $\mathrm{I}(\mathrm{T})$ \\
\hline Alfashin & 100 & 2.12 & 6.73 & 8.93 & $\begin{array}{c}0.0006 \\
(0.0005-0.0007)\end{array}$ & $\begin{array}{c}0.002 \\
(0.001-0.002)\end{array}$ & 1 & $\mathrm{~S}$ \\
\hline Ehnasia & 100 & 1.91 & 13.06 & 6.89 & $\begin{array}{c}0.01 \\
(0.005-0.01)\end{array}$ & $\begin{array}{c}0.02 \\
(0.01-0.02)\end{array}$ & 16.6 & II \\
\hline
\end{tabular}

Table 4: Mean Esterase activity \pm SD of $R$. $(B)$. annulatus larvae from different localities in Benisuef province:

\begin{tabular}{|c|c|}
\hline Locality & $\begin{array}{c}\text { Mean of esterase activity } \\
\pm \text { SD }\end{array}$ \\
\hline Alfashin & $1.024 \pm 0.014$ \\
\hline Ehnasia & $2.373 \pm 0.058$ \\
\hline Beni-Suef & $1.67 \pm 0.155$ \\
\hline
\end{tabular}




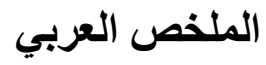

\section{ليليان محروس - أسماء كامل

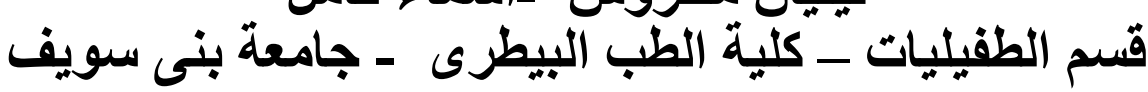

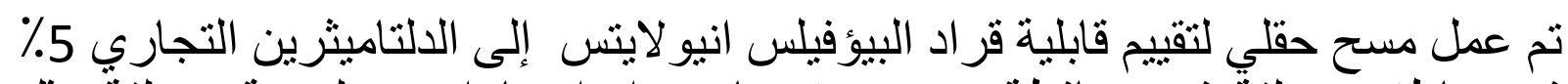

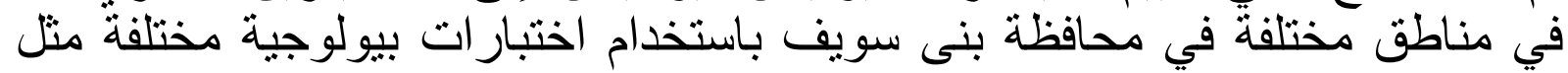

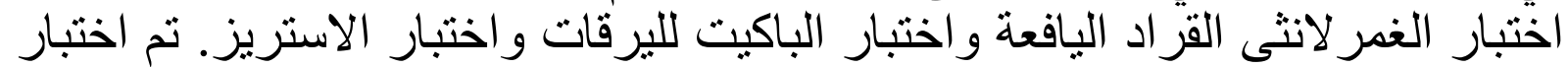

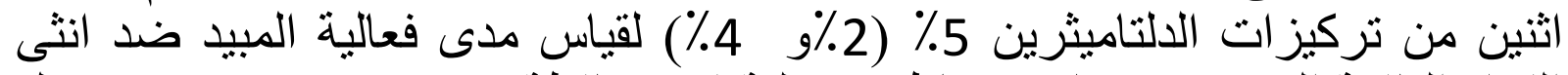

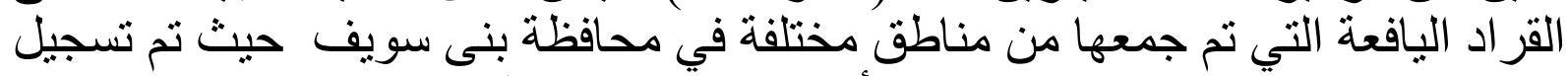

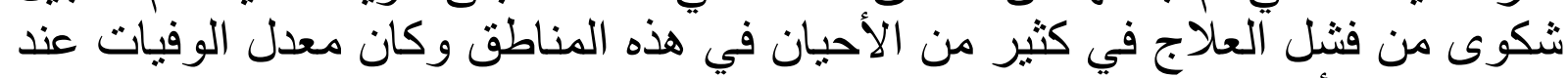

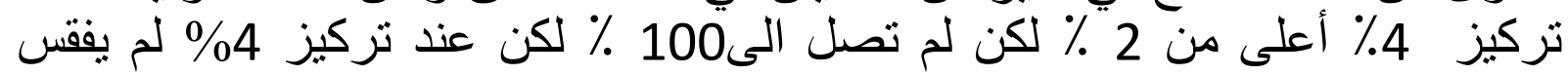

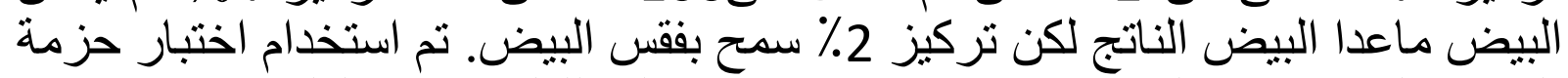

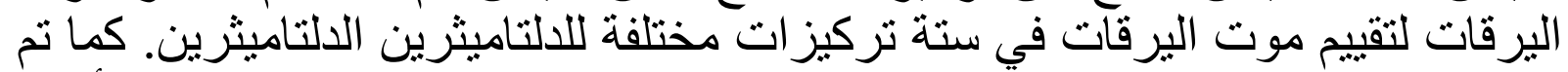

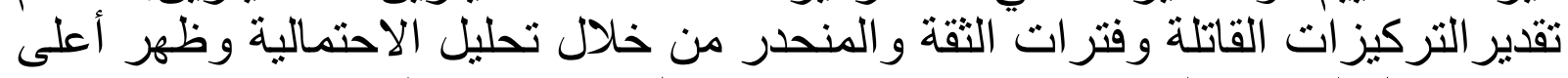

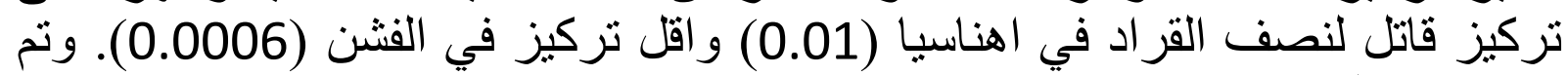

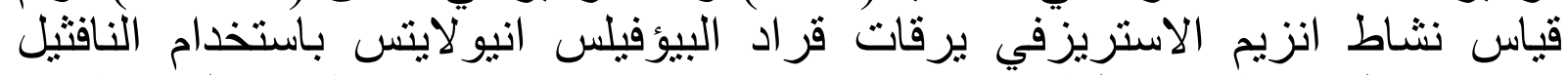

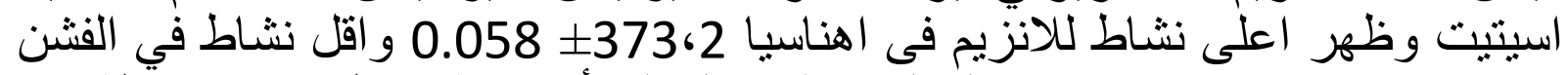

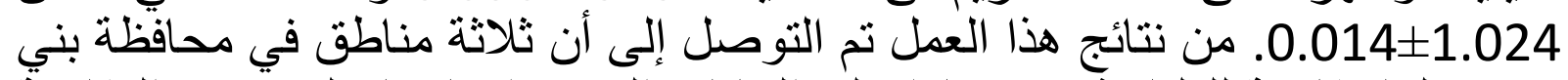

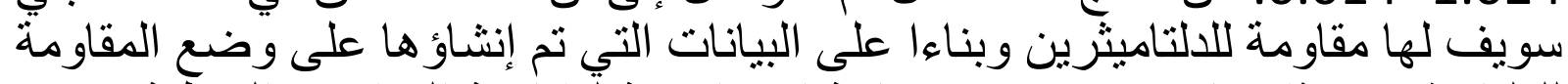

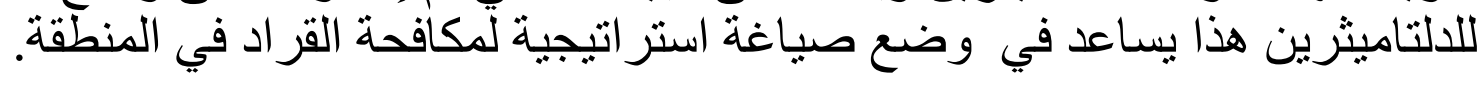

